\title{
TDIC NA EDUCAÇÃO BÁSICA: PERSPECTIVAS E DESAFIOS PARA AS PRÁTICAS DE ENSINO DA ESCRITA
}

\author{
TDIC IN BASIC EDUCATION: \\ PERSPECTIVES AND CHALLENGES FOR \\ WRITING TEACHING PRACTICES
}

\section{Ana Lúcia Tinoco Cabral ${ }^{*}{ }^{* *}$ Nelci Vieira de Lima** Sílvia Albert ${ }^{\star \star * *}$}

\section{RESUMO}

Em continuidade às abordagens para o ensino de escrita preconizadas pelos $\mathrm{PCN}$, que já mencionavam a questão da inserção das TDIC no ensino, a Base Nacional Comum Curricular - BNCC (BRASIL, 2018), mais recente documento norteador da educação básica no Brasil, confere centralidade aos multiletramentos, fazendo das TDIC protagonistas de muitos processos educativos. Dito isso, este trabalho focaliza as TDIC nas práticas de escrita e tem por objetivo identificar o que estabelece a BNCC relativamente aos gêneros digitais e à inserção das TDIC para Língua Portuguesa, e, nesse contexto, o ensino e a aprendizagem da escrita; analisar posts de fotos do perfil studigram, considerando a multimodalidade, a interação e o processo de autoria; e apresentar reflexões sobre perspectivas e desafios para as práticas de escrita na escola, propondo possíveis estratégias de ensino da escrita a partir da aplicação das práticas de linguagem usadas no studigram. $\mathrm{O}$ trabalho fundamentase teoricamente nos preceitos da própria BNCC em diálogo com autores que tratam de questões de multiletramentos e multimodalidade no ensino (ROJO, 2013; 2016; ROJO; MELO, 2014; ROJO; BARBOSA, 2015; PIMENTA \& BOMFANTE DOS SANTOS, 2017) e da escrita (COULMAS, 2014; FLUSSER, [1989] 2010). As análises indicam que, em sua atuação nas redes sociais, os jovens já dominam processos multimodais de produção de sentidos, já se assumem como responsáveis por suas produções e contemplam seus leitores em seus posts; as reflexões e as propostas apresentadas apontam para a importância de inserção das TDIC como forma de envolver os estudantes nas práticas de escrita, fazendo com que eles assumam o papel de curadores e autores nas práticas de escrita, conforme preconiza a

\footnotetext{
* Universidade de São Paulo, USP, São Paulo, SP, Brasil.

** IP-PUCSP, São Paulo, SP, Brasil. altinococabral@gmail.com

Orcid: https://orcid.org/0000-0001-6417-2766

*** Universidade Cruzeiro do Sul, UNICSUL, São Paulo, SP, Brasil. nevieira@gmail.com

Orcid: https://orcid.org/0000-0001-5883-804X

**** Universidade Cruzeiro do Sul Virtual, UNICSUL, São Paulo, SP, Brasil. silvia.augusta.albert@ gmail.com

Orcid: https://orcid.org/0000-0002-1237-8399
} 
BNCC; as reflexões apresentadas indicam também a importância da formação do docente para atuar em um mundo primordialmente tecnológico, cujas premissas e processos os estudantes, nativos digitais, já dominam.

Palavras-chave: BNCC; multiletramentos; escrita.

\section{ABSTRACT}

In continuity with the approaches to teach writing advocated by PCNs, which already mentioned the issue of the insertion of the TDIC in teaching, the National Curricular Common Base - BNCC (BRASIL, 2018), whitch is the most recent guiding document of basic education in Brazil, assingns multiliteracy to play the main role of many educational processes. Having said that, this work focuses on the TDIC in writing practices and aims to identify what establishes the BNCC in relation to the digital genres and the insertion of the TDIC into Portuguese Language, and, in this context, teaching and learning of writing. The study analyzes studigram's profiles posts, takin in consideration multimodality, interaction and authoring process and presents reflections on perspectives and challenges to the writing practices at school, proposing possible strategies usin this social network. The paper is based theoretically on the BNCC's own precepts in dialogue with authors dealing with multiliteracy and multimodality issues (ROJO, 2013; 2016; ROJO; MELO, 2014; ROJO; BARBOSA, 2015; PIMENTA \& BOMFANTE DOS SANTOS, 2017) and writing (COULMAS, 2014; FLUSSER, [1989] 2010). The analyses indicate that, in their work in social networks, tenages have already mastered multimodal processes of sense production, they assume responsibility for their productions and envisage their readers in their posts. The reflections and the proposals presented point out to the importance of insertion of TDIC as a way to get students involved in writing practices, making them assume tehmselves as curators and authors in writing practices, as advocated by BNCC. Also the reflections indicate the importance of the participation of teachers as coordinators of the processes and their need to be qualified and trained to act in a world that is primarily technological, whose premises and processes students, who are digital natives, master already.

Keywords: BNCC; multiliteracy; writing

\section{CONSIDERAÇÕES INICIAIS}

Neste segundo decênio do século XXI, vimos nossas vidas serem invadidas pelas tecnologias digitais de informação e comunicação (TDIC); mais do que isso, elas se tornaram uma extensão de nossa vivência, sobretudo as redes sociais, as quais norteiam a participação cidadã, conforme já expôs Lion (2006). De acordo com Georges (2010), as redes sociais propiciam a construção de uma identidade e exigem do usuário que ele negocie constantemente essa identidade com os demais usuários.

Os jovens são os grandes protagonistas dessa verdadeira revolução digital, as TDIC lhes proporcionam liberdade: eles se comunicam livremente e têm amplo acesso a informações das mais diversas áreas do saber. Além disso, as mídias sociais proporcionam a construção de sua identidade, por meio do sentimento de 
pertencimento a determinado grupo social. Outro fator que deve ser ressaltado é que há uma geração que é nativa digital, para a qual lidar com as TDIC é algo totalmente corriqueiro; conforme Baptista (2017), são considerados nativos digitais, a geração $Z$, ou seja, aqueles que nasceram entre meados dos anos 1990 e início dos anos, já com a web e as tecnologias móveis. Diante desse contexto, a escola, em seus processos educativos, não pode, por conseguinte, ignorar esse mundo tão atraente, principalmente às gerações mais jovens. Ao contrário, é importante que as TDIC sejam encaradas como ferramentas capazes de colaborar para a formação dos jovens estudantes que frequentam a escola básica.

Se os PCN tocaram de leve na questão da inserção das TDIC no ensino, o mais novo documento norteador da educação básica no Brasil, a Base Nacional Comum Curricular, doravante BNCC (BRASIL, 2018), traz fortemente à tona a questão do letramento digital, fazendo das TDIC protagonistas de muitos processos educativos. $\mathrm{O}$ documento prevê, para cada campo de atuação humana, o desenvolvimento de habilidades e competências voltadas para as práticas sociais contemporâneas, o que inclui, decerto, a aquisição da capacidade do estudante de "produzir, de configurar, de disponibilizar, de replicar e de interagir" (BRASIL, 2018, p. 68) a partir dos mais diversos gêneros multissemióticos e multimidiáticos.

Diante dessa realidade, cabe perguntar: Como as redes sociais podem contribuir para as práticas escolares de ensino da Língua Portuguesa? Como utilizálas em aula? Como desenvolver a competência escritora, na educação básica, a partir de práticas de multiletramentos já vivenciadas pelos estudantes fora da escola? Essas três perguntas orientam o desenvolvimento deste trabalho.

Assim, elegemos como objeto de estudo o studigram, um perfil temático, da rede social Instagram. O studigram é um perfil aberto, criado por adolescentes e voltado para a produção e divulgação de conteúdos autorais, relacionados às práticas de estudo do cotidiano escolar.

Para responder às nossas perguntas, tendo como corpus de estudo o studigram, estabelecemos três objetivos: 1. identificar o que estabelece a BNCC relativamente aos gêneros digitais e à inserção das TDIC para a área de linguagens, na qual se inclui a Língua Portuguesa, e, nesse contexto, o ensino e a aprendizagem da escrita; 2. analisar posts do studigram, considerando a multimodalidade, a interação e o processo de autoria; 3 . apresentar possíveis estratégias para o trabalho com a escrita na educação básica, com base nas análises do studigram e em diálogo com os preceitos da BNCC acerca dos gêneros digitais e as TDIC, levando em conta os multiletramentos, a multimodalidade e seu impacto no ensino e aprendizagem da escrita nos anos finais do Ensino Fundamental. 
Para dar conta dos objetivos propostos, organizamos este artigo em quatro partes, além destas considerações iniciais e das finais: na primeira seção, expomos brevemente os princípios norteadores da BNCC e apresentamos o que preconiza o documento relativamente às TDIC no ensino da escrita nas aulas de Língua Portuguesa; na segunda, expomos as perspectivas teóricas e conceitos basilares que fundamentam nossas reflexões, análises e proposta, no que concerne à escrita, aos gêneros digitais, às noções de multiletramento e multimodalidade que a envolvem; na terceira seção, analisamos imagens de posts de usuários do perfil studigram, apresentando suas características e observando exemplos reais de páginas do Instagram; por fim, na quarta seção, propomos algumas possibilidades de utilização desse gênero nas aulas de Língua Portuguesa, de modo a oferecer ao professor sugestões de aplicação das TDIC para o ensino e a aprendizagem da escrita, apresentando reflexões a respeito da pertinência do studigram para as práticas escolares em sala de aula.

\section{A BNCC, PRINCÍPIOS GERAIS E TDIC}

Há muito era esperado que o Brasil tivesse uma base nacional comum para a educação básica. Assim, de caráter normativo, a BNCC tem como marcos legais a Constituição Federal, de 1988, e a LDB 9396/94, documentos que preconizam a necessidade de fixação de conteúdos mínimos para a educação básica, tendo em vista o comum e o diverso, ou seja, apesar da fixação mínima de conteúdos básicos, os currículos garantem o respeito à diversidade, uma vez que cada estado brasileiro, em parceria com seus municípios, tem hegemonia para construí-los, de acordo com suas reais necessidades.

Pedagogicamente, a BNCC tem como enfoque o desenvolvimento de competências e habilidades, de modo a garantir aos alunos não só a aquisição do saber, mas, sobretudo, a mobilização desse saber para atuação na sociedade. Devemos considerar, em consonância com o que preconiza a BNCC, que a participação dos cidadãos se dá em diversas esferas de atividade, o que justifica a divisão do documento em campos de atuação ou esferas discursivas, sendo estes:

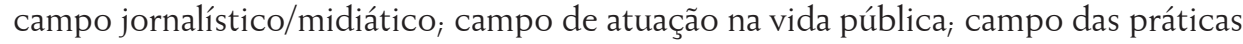
de estudo e pesquisa; campo artístico-literário.

Em relação às TDIC, o documento reconhece o desafio imposto pela sociedade contemporânea à educação, levando em conta que, apesar do contexto tecnológico disponibilizar uma infinidade de informações, cabe ao usuário saber fazer a curadoria dessas informações. O termo curadoria é oriundo do campo das 
artes e diz respeito à checagem de dados, comparação de informações e de sites. Sendo assim, o usuário das TDIC deve saber avaliar para selecionar com criticidade as fontes, além de agir com ética, tanto ao compartilhar informações como ao interagir nas mídias sociais, evitando a intolerância e o discurso de ódio. Esse objetivo se comprova nesta competência, prevista para a área de Linguagens na BNCC:

Compreender e utilizar tecnologias digitais de informação e comunicação de forma crítica, significativa, reflexiva e ética nas diversas práticas sociais (incluindo as escolares), para se comunicar por meio das diferentes linguagens e mídias, produzir conhecimentos, resolver problemas e desenvolver projetos autorais e coletivos. (BRASIL, 2018, p. 65)

Em relação aos contextos digitais, a BNCC aponta, para o ensino da Língua Portuguesa no Ensino Fundamental - anos finais, o trabalho com diversos gêneros provenientes da cultura juvenil, entre os quais são mencionados: vlog, fotorreportagem, detonado, podcast, slam, vídeo, playlists comentadas, fanfics, fanzines, e-zines, fanvídeos, fanclipes, posts em fanpages, trailer honesto, vídeominuto (BRASIL, 2018). A orientação da BNCC é de que o trabalho com os gêneros siga sempre os eixos: leitura, produção de textos, oralidade e análise linguística/ semiótica, dentro dos quais estão elencadas as habilidades previstas para cada ano, havendo também aquelas comum a todos os anos. O diferencial, em relação aos PCN, é que, na BNCC, o foco centra-se mais nos campos de atuação do que nos gêneros propriamente ditos. Assim, determinado gênero pode ser pertinente a mais de um campo e adaptar-se ao uso que se faz dele em determinada esfera discursiva.

Interessa-nos, sobretudo, neste trabalho, como será exposto nas reflexões sobre a aplicação nas práticas de sala de aula apresentadas na quarta seção, o campo das práticas de pesquisa e estudo, para o qual o documento prevê o "desenvolvimento de habilidades e aprendizagens de procedimentos envolvidos na leitura/escuta e produção de textos pertencentes a gêneros relacionados ao estudo, à pesquisa e à divulgação científica" (BRASIL, 2018, p. 150). Ainda para esse campo, é previsto, além de uma articulação entre as áreas do saber, que os alunos se engajem em projetos de escolhas pessoais. Além dos gêneros típicos do letramento da letra e do impresso, esse campo de atuação não deixa de abranger gêneros próprios da cultura digital e das culturas juvenis, entre os quais são citados: "relato (multimidiático) de campo, documentário, cartografia animada, podcasts e vídeos diversos de divulgação científica" (BRASIL, 2018, p. 151).

Em relação ao desenvolvimento da competência escrita, dentro de cada campo, é previsto que o trabalho envolva ações como: planejar, produzir, revisar, editar o texto e, em muitos casos, publicá-lo, considerando sempre o contexto de produção 
e as regularidades dos gêneros em termos de suas construções composicionais e estilos. Observamos que o trabalho com a escrita é minucioso e exige do professor um planejamento rigoroso das aulas, para que, ao estudar determinado gênero, os alunos sejam levados a praticarem sua escrita de forma significativa, a fim de que tomem posse dessa prática social. Além disso, cabe ressaltar que cada etapa desse trabalho exige ações precisas, coletivas e individuais, como: pensar no contexto de produção, nas características do gênero, no plano de texto e, por fim, na revisão e edição. Essas duas últimas ações envolvem aspectos pontuais de uso da língua e da gramática, tendo que se levar em conta o nível linguístico exigido pelo gênero, que poder ir do mais informal ao mais formal, o que levará o aluno a uma importante reflexão linguística.

De fato, o trabalho com a produção escrita é, por si só, bastante complexo, e se torna ainda mais quando nas práticas desse trabalho estão envolvidos aspectos da multimodalidade e dos multiletramentos, uma vez que não cabe só o desenvolvimento do letramento da letra e do impresso, mas também o letramento digital, com suas múltiplas semioses, conceitos que serão desenvolvidos na próxima seção deste trabalho. Lembramos, com Rojo (2013, p. 20), que "esses novos escritos obviamente dão lugar a novos gêneros discursivos quase diariamente: chats, páginas, twits, posts, ezines, epulps, fanclips, etc". Esses novos gêneros emergem numa correspondência direta com as transformações da sociedade, demandas de comunicação e relacionamento e são suportados pelas possibilidades oferecidas pelo constante desenvolvimento de novas tecnologias.

Tendo em vista que é papel primordial da escola letrar o aluno para o impresso, levando-o ao domínio da escrita e tornando-o um cidadão capaz de atuar socialmente por meio dos gêneros nos diversos campos, consideramos grande o desafio que as multissemioses da sociedade contemporânea têm imposto à escola. No entanto, tratamos, neste artigo, não só dos desafios, mas também das perspectivas. Uma vez que os estudantes da educação básica, pertencentes à geração $Z$, chegam à escola, muitas vezes, com domínio de muitas práticas sociais de uso da escrita em contexto tecnológico, afirmamos que tais práticas podem e devem ser incorporadas em sala de aula, como aliadas para o desenvolvimento da competência escritora.

Na próxima seção, refletiremos sobre a escrita em contexto digital, os multiletramentos e a multimodalidade. Procuramos, assim, aprofundar teoricamente esses conceitos, a fim de fundamentá-los não só por meio da análise do perfil studigram, mas também a partir da proposta de aplicação dessa prática multimodal e multissemiótica na educação básica. 


\section{A ESCRITA NO CONTEXTO DIGITAL: MULTILETRAMENTOS E MULTIMODALIDADE}

A hipermodernidade, conceito postulado por Lipovetsky (2004) juntamente com outros autores como Charles (2009), constitui um conceito que pressupõe a radicalização da modernidade e não a sua superação. A hipermodernidade não trouxe só avanços tecnológicos, mas também mudanças de comportamento, formas de interação e maneiras de aprender, de ler e de produzir textos, construindo sentidos também de formas diversas. Concordamos com Rojo e Melo (2014), quando afirmam que algumas invenções tecnológicas incorporaram-se ao nosso cotidiano, influenciando nossas práticas sociais de linguagem de tal forma, que parecem ter se constituído como extensões de nosso corpo e de nossa mente, como se fossem nossas mãos, ouvidos, e diríamos, também, nossa boca. Concordamos igualmente com Fogel e Patino (2013, p. 9), para quem, embora o "homo sapiens" não tenha se tornado "o homo numericus", vivemos "numa época nova, e que não nos deixa nenhuma trégua: o tempo da conexão permanente ${ }^{\prime \prime}$. No entanto, conforme atesta Coulmas (2014), é preciso olhar para além das implicações tecnológicas da era digital. Estamos, na verdade, lidando "com uma profunda mudança cultural com consequências para a língua e a sociedade, a economia e a política" (COULMAS, 2014, p. 162).

Nesse contexto, é importante que a instituição escolar se coloque como um espaço dinâmico, entre a tradição e a transição, a fim de preparar os estudantes, futuros profissionais, tanto para esse mundo digital de ritmos velozes, para as tecnologias digitais de informação e de comunicação (TDIC) e o uso adequado de suas ferramentas, quanto para essa sociedade de identidades múltiplas e de grande diversidade cultural.

É fato que a escola ainda privilegia a cultura considerada "culta", em detrimento de práticas que circulam nos ambientes da cultura de massa e digital, conforme defendido por Rojo e Barbosa (2015); privilegia, assim, o letramento da letra. A sociedade contemporânea, no entanto, convive com diferentes culturas e com os hibridismos que delas resultam, o que torna inadequado pensar em dicotomias como cultura erudita x popular; canônica x de massa, pois o que encontramos, cada vez com mais frequência, são essas culturas hibridizadas em práticas sociais de linguagem que utilizam diferentes modalidades.

1. (...) dans une époque neuve, et qui ne nous laisse aucun répit: le temps de la connexion permanente. (tradução nossa) 
Essa realidade nos leva ao conceito de multiletramentos, da perspectiva do Grupo de Nova Londres², que implica pensar em duas acepções para esse "multi": tanto "a multiplicidade de linguagens, semioses e mídias envolvidas nos textos multimodais contemporâneos quanto a pluralidade e a diversidade cultural trazidas por autores/leitores" (ROJO, 2013, p.14) para a produção de sentidos. Os multiletramentos desafiam a escola a desenvolver novas competências, como negociar "com uma crescente variedade de linguagens e discursos, interagir com outras linguagens para criar sentidos para a multidão de dialetos, discursos, estilos, registros presentes na vida cotidiana" (ROJO, 2013, p.17) na web e em rede. Para essa autora, é necessário preparar os estudantes para enfrentar as dificuldades que a diversidade de culturas e linguagens oferece quando se quer estabelecer diálogos construtivos nas diferentes redes sociais que utilizam TDIC.

Vale destacar que a noção de multimodalidade ainda apresenta variações, tendo em vista perspectivas diferentes, apontadas inclusive por Rojo (2013): por um lado, essa noção tende a ser abordada por uma "gramática visual", da mesma forma como se trata gramaticalmente a língua (falada ou escrita), que abarcaria as outras semioses e mídias (pintura, fotografia, vídeo música, dança) buscando tanto regularidades estruturais como gramaticais, tal como propôs Kress (2006); por outro, tende a ser pensada da perspectiva semiótica, proposta por Santaella (2001), que a aborda como variações de percepção sensorial, oriundas de diferentes modos de produzir sentidos, por meio de diferentes tecnologias.

De outra perspectiva ainda, Rojo (2013) destaca que as práticas de linguagem se dão sempre de maneira situada, em determinadas situações de comunicação que são definidas por esferas ou campos de atuação (científico jornalístico, literário etc.), devendo-se levar em conta esse fato como o mais importante. Essa proposição encontra anuência em Pimenta e Bomfante dos Santos quando asseveram que "as linguagens que se materializam nos textos são articuladas com o propósito de atender uma função em um contexto situacional" (PIMENTA; BOMFANTE dos SANTOS, 2017, p.396). De fato, no que diz respeito aos textos,

numa comunidade, eles têm de realizar as mais diversas funções acionais e comunicativas. Para as funções sociais padronizadas, dispomos de categorias de textos (ou seja, de padrões textuais), e essas, por sua vez, ao serem realizadas nas comunicações concretas, têm que ser adaptadas às diferentes condições prévias e às finalidades individuais que caracterizam uma dada situação (SANDIG, 2009, p.47).

2. O Grupo de Nova Londres é formado por estudiosos, principalmente da Linguística e da Educação, de três países, Estados Unidos, Grã-Bretanha e Austrália, conforme Rojo (2013). 
Dessa forma, no contexto atual, as esferas ou campos de atuação se valem de diferentes mídias (impressa, radiofônica, digital) e, respectivamente, de diferentes recursos semióticos, tendo em vista ainda as possíveis combinatórias entre eles. Um exemplo desse hibridismo e articulação para produção de sentidos são os blogs, que misturam diversas semioses na produção dos sentidos que promovem a interação entre os usuários participantes: notícia escrita em hipertexto, imagens, fotos, gráficos, áudios, podcasts, tudo isso articulando os papéis de autor/leitor, que se alternam nas interações do blog, inclusive por meio do acesso pelas redes sociais; esse conjunto de semioses produz e renova sentidos e conhecimentos. Por isso é que, atualmente, do ponto de vista textual, compreende-se a multimodalidade como "integrada ao texto e não como um acessório a ele, uma informação suplementar, como muitas vezes tendemos a considerar" (CABRAL, 2013a, p.94). Dessa perspectiva, a multimodalidade é constitutiva do texto.

Assim, vale destacar que, nos gêneros multimodais, não há apenas uma justaposição de semioses e de sentidos, mas uma articulação entre as diferentes modalidades para uma integração de sentidos. De acordo com Pimenta e Bomfante dos Santos (2017, p.396), "os textos multimodais devem ser vistos, pois, como produção de significado em múltiplas articulações". Para essas autoras, os usuários recriam constantemente essas diferentes linguagens e mídias, "como recursos representacionais dinâmicos presentes nos textos contemporâneos, quando atuam visando atingir seus propósitos culturais" (PIMENTA; BOMFANTE DOS SANTOS, 2017, p.396) e, acrescentamos: comunicacionais e interativos. Afinal, as diversas categorias de textos "ao serem realizadas nas comunicações concretas, têm que ser adaptadas às diferentes condições prévias e às finalidades individuais que caracterizam uma dada situação" (SANDIG, 2009, p.47).

Dessa perspectiva, devemos considerar também a possibilidade de publicação conferida a todos os usuários das TDIC, tanto de publicar algo novo, quanto de comentar a publicação de outros usuários, interferindo no texto do outro, agindo simultaneamente como leitor e autor, ou como leitor-autor. De fato, como atestam Ouerfelli e Ghourabi (2015), os estudantes, em suas práticas escolares, recorrem aos meios digitais tanto para buscar informações como para se comunicar e estabelecer trocas com seus colegas; por isso, essas autoras afirmam que as TDIC "constituem agora uma ferramenta essencial e uma parte integrante da vida tanto social como escolar de numerosos estudantes" ${ }^{\prime \prime}$ (OUERFELLI; GHOURABI, 2015, p. 89).

3. (...) constituent maintenant des outils essentiels et une partie intégrante de la vie tant sociale que scolaire de nombreux étudiants. (tradução nossa) 
De acordo com Rojo (2016), os novos letramentos não correspondem apenas ao uso de TDIC, mas dizem respeito, sobretudo, a um novo conjunto de valores que alteram aqueles do letramento convencional, da letra, do impresso. Se neste último, são valorizados a autoria individual, a raridade, o ineditismo, o controle da distribuição dos textos, nos novos letramentos, vigoram valores como a colaboração, a participação contínua, a relação em rede, a distribuição mais ampla possível dos textos, a apreciação (curtir, comentar etc.).

Tendo em vista o novo conjunto de práticas sociais de linguagem, novos letramentos e valores, que estão presentes na vida pública e privada de todos, faz-se necessário que eles estejam presentes também na escola, como objetos de estudo e de análise crítica. Mais uma vez, concordamos com Rojo (2016) que não se trata de formar usuários funcionais, que dominam ferramentas e programas, como muitos já chegam prontos à escola, mas torná-los leitores críticos, produtores de sentidos, tanto na leitura quanto na produção de textos mutissemióticos e de novos gêneros digitais.

Vale lembrar que estamos vivenciando uma violenta revolução sem precedentes na longa história da cultura escrita, conforme afirma Chartier (1998), um dos mais importantes estudiosos da história do livro e da leitura. Esse pesquisador estabelece uma analogia entre o surgimento da imprensa e a invenção do e-book, destacando que ambos constituem uma revolução técnica, sendo o e-book uma revolução da plataforma da escrita e da leitura. Essas mudanças revolucionárias, conforme postula Chartier (2011), desafiam práticas e categorias até então definidoras da relação com a escrita, estabelecidas desde o século XVIII.

Coulmas (2014) indaga para onde caminha a escrita e, com isso, atualiza a pergunta sobre a possibilidade de futuro para a escrita, proposta pelo filósofo tchecobrasileiro Flusser ([1989], 2010), que ao final da década de 1980, antes mesmo do advento da internet, já antevia profundas mudanças em relação à escrita no mundo que se tornava tecnologicamente digital. $\mathrm{O}$ linguista responde afirmativamente à questão do filósofo, ao afirmar que "a dependência da sociedade contemporânea para com a escrita é maior do que nunca" (COULMAS, 2014, p.162).

Além de sublinhar o uso mais constante da escrita nas novas mídias e redes sociais na web, Coulmas (2014) elenca uma série de modificações na forma de escrever atual que são específicas à mudança tecnológica, como novos registros e variação estilística: grafias desviantes, escrita na variedade não padrão da língua, abreviações, cortes de palavras e frases, que dizem respeito a inovações linguísticas e lexicais, com influências multimodais. Todas essas transformações, afirma esse autor, têm potencial para abalar os padrões da escrita, mas ao mesmo tempo "de 
fortalecer esses mesmos padrões ao democratizar o acesso à escrita" (COULMAS, 2014, p.167).

Há uma comunidade crescente de novos escritores, o que certamente terá efeitos no desenvolvimento da linguagem, como já temos acompanhado em incontáveis textos de tuítes e de redes sociais, como nas páginas dofacebook, em que são lançados, continuamente, textos de domínio público que apresentam hábitos, sentimentos e preferências de centenas de milhões de pessoas. Concordamos com Coulmas (2014) que a internet tornou mais fácil e rápido distribuir informações pelas TDIC.

É importante ressaltar, no entanto, como aponta o próprio autor, que "a quantidade afeta a qualidade em muitas dimensões" (COULMAS, 2014, p. 181 e 182). Uma delas é a velocidade, que imprime uma imediatez que não fazia parte da escrita, aproximando-a da oralidade, no que ela traz de informal e de impermanente, embora "as palavras confiadas à internet deixem sempre marcas indeléveis" (COULMAS, 2014, p. 181 e 182). Se quisermos entender os modos de escrever da sociedade contemporânea, é necessário estudar o comportamento online dos jovens. Eles não se incomodam com os anúncios que pululam em meio aos textos no ambiente digital e acham normal que a escrita pressuponha o diálogo com outros e que possa "ser tão informal e efêmera como a fala" (COULMAS, 2014, p.185).

Flusser preconizava que a escrita do futuro solicitaria uma transcodificação, isto é, uma reaprendizagem, pois passaríamos "do mundo das regras lógicas para o das matemáticas e, sobretudo, do mundo da linha para o das redes formadas por pontos" (FLUSSER, [1989]2010, p.168). Parafraseando o filósofo, estamos passando da escrita em sua forma "analógica" (modo que varia e evolui no tempo de maneira contínua, como a escrita acontece até o mundo da impressão) para uma escrita "digital" (modo que consiste em dividir uma grandeza em pequena frações, em intervalos regulares e quantificá-las atribuindo-lhes um código informático binário, 0 e 1, como a escrita atual, retificada, hipertextual do mundo da web), fato que em si não apresenta nenhuma ameaça, apenas confirma que a história da escrita, como tecnologia humana, é sempre passível de mudanças, devido a novas descobertas técnico-científicas e demandas sociais.

Vale ressaltar, no entanto, que essa transição entre a cultura da escrita "analógica" e alfabética para o contexto da hipermodernidade e para a cultura da escrita "digital", deve ser acompanhada de uma mudança de vida e de pensamento, ou seja, de valores e posturas, como afirmamos anteriormente neste texto, para que não aconteça uma queda na "barbárie analfabética", como já conjecturava Flusser ([1989], 2010, p. 169). É preciso se apropriar da escrita e de suas características 
anteriores à web para que o uso das TDIC na educação não seja meramente instrumental.

Esse é, a nosso ver, o grande desafio da escola na formação da geração Z, de nativos digitais, e daquelas que irão sucedê-la. Constituir-se como o espaço de transição e de tradição, garantindo tanto a reflexão sobre o uso da linguagem tendo em vista as dimensões ética, estética e política desse uso - quanto sobre a constituição das interações e dos processos diferentes de escritas diversas. Além disso, desenvolver novas e diferentes habilidades que levem os jovens não só "a ressignificar as cristalizações letradas" (ROJO, 2013, p.18) como também a "lidar de forma crítica com os conteúdos que circulam na internet " conforme preconiza a BNCC (BRASIL, 2018, p. 66).

É fundamental que a escola estabeleça um diálogo produtivo com a web, incorporando as práticas de linguagem contemporâneas que impõem novas estéticas (multimodais), que devem ser discutidas, assim como deve refletir sobre uma nova ética, reformulando a ideia de propriedade e direitos do autor, que se diluem no espaço de navegação da web, configurada como território de compartilhamento e colaboração. Para que não se confirme o vaticínio de Flusser ([1989]2010), ou seja, a "barbárie analfabética", é preciso que a escola assuma o compromisso de formar analistas de conteúdos críticos e não apenas consumidores de informação; produtores de sentidos responsáveis pelo que dizem e não despejadores de opiniões.

Em resumo, é importante pensar em uma pedagogia da escrita que leve o autor/leitor a desenvolver competências técnicas; a entender como operam as tecnologias e os diferentes gêneros, criados ou inseridos na web, para a produção de sentidos; a tornar-se um analista e crítico das muitas informações disponíveis na web, praticando a curadoria, como exercício necessário para exercer seu papel de autor/ leitor em diferentes práticas sociais de linguagem; a utilizar o que foi aprendido para instituir novas formas de configuração, disponibilização, réplica e interação. Sendo assim, trata-se de uma pedagogia da escrita que envolve uma prática situada, tendo em vista uma prática transformadora, de acordo com o que preconiza Rojo (2012).

\section{A REDE SOCIAL STUDIGRAM: ESCRITA, INTERAÇÃO E MULTIMODALIDADE}

Criado em 2010, pelo brasileiro Mike Kriger e pelo norte-americano Kevin Systrom, o Instagram é uma rede social pensada, inicialmente, para ser um aplicativo, disponível apenas para aparelhos da Apple, que seria usado para aplicar filtros às imagens e compartilhá-las no Facebook e Twitter. Em pouco tempo, no entanto, o aplicativo foi modificado e tornou-se uma rede social, ganhando não só uma versão 
para Android, como também mais e mais adeptos. Assim como nas demais redes sociais, no Instagram, as pessoas se conectam formando uma rede de interesses, compartilhando e comentando fotos, divulgando negócios ou manifestando sua posição política, criando uma esfera virtual de convivência social. Há duas maneiras de compartilhar imagens ou textos na rede Instagram, pelo feed, onde imagens, fotos ou vídeos entram na página dos seguidores e ficam visíveis a todos, ou nos storys, uma espécie de espaço transitório, no qual a publicação tem pouca durabilidade e, para ser acessada, deve ser clicada pelo usuário. O Instagram possui perfis fechados e perfis abertos. Os fechados são restritos aos usuários "aceitos" pelo responsável pelo perfil e somente esses usuários têm acesso aos conteúdos publicados. Já os perfis abertos têm caráter público, isto é, acesso livre e irrestrito a todos os usuários do Instagram.

Sendo o Instagram uma rede social organizada por perfis, o studigram constitui-se como um perfil temático e aberto dentro dessa rede, reunindo usuários adolescentes que produzem e divulgam conteúdos de estudo, produzidos por eles próprios, além de dar dicas e estratégias para a organização dos estudos. Os usuários do studigram caracterizam-se também pela preocupação com a disposição de elementos multimodais e com a caligrafia. Trata-se de uma tecnologia digital de comunicação e informação, multimodal, que une diversas práticas de letramento, do impresso ao digital: produção de material manuscrito, como resumos, mapas mentais, tutoriais com dicas de caligrafia, dicas de como se organizar para estudar; produção de fotos e edição de imagens, o que implica preocupação com o enquadramento, cor e disposição dos elementos na imagem; publicação das fotos no feed ou nos storys; interação por comentários, como curtidas, likes, emojis; interação por chat, usando o direct que permite trocar mensagens instantâneas com os seguidores; uso da comunicação oral por meio das lives, transmissões de vídeos em tempo real, que também podem ficar gravadas e disponibilizadas na rede.

Relativamente ao campo de atividade, cumpre observar que o Instagram, espaço que abriga o studigram, insere-se no campo de atuação na vida pública (BRASIL, 2018); dentro desse campo, o studigram se insere no campo das práticas de estudo e pesquisa. Esse diálogo entre campos de atuação assume dimensões formativas importantes, na medida em que propicia aos estudantes circular entre campos, atuar de forma participativa compreendendo as práticas de linguagem de uma perspectiva situada, nas quais as produções dos jovens circulam de forma dinâmica na vida social e nas práticas de estudo, voltadas para a vida escolar.

A partir da descrição do funcionamento das postagens, é possível perceber como o studigram se constitui em sua multimodalidade, uma vez que permite ao 
usuário uma combinatória de práticas multissemióticas, por meio das quais interage com os outros usuários, formando o que podemos chamar de uma rede de aprendizagem colaborativa. $\mathrm{O}$ grupo que frequenta essa rede ora se interessa pelos estudos ora pelas dicas de como produzir uma bela caligrafia, o que é chamado por eles de lettering.

Os posts que apresentamos, a seguir, em nossas análises foram selecionados do studigram. Para as análises, buscamos nesse perfil exemplos de posts que contivessem orientações e dicas de estudo, ignorando aqueles que focavam apenas em técnicas de caligrafia. Feita essa primeira seleção, refinamos a escolha, para posts que apresentassem estratégias de sumarização de conteúdos: resumos, esquemas e mapas mentais. Embora o studigram seja um perfil público e aberto, tomamos o cuidado de eliminar a identificação dos usuários, resguardando a sua privacidade.

$\mathrm{Na}$ imagem 1, a seguir, podemos observar as múltiplas semioses envolvidas no uso do studigram, entre as quais destacamos a prática de letramento da letra que se concretiza na produção do material escrito, no gênero resumo, e na preocupação com a divulgação da imagem do trabalho, cujo enquadramento da foto destaca as canetas, instrumento fundamental para a produção do manuscrito.

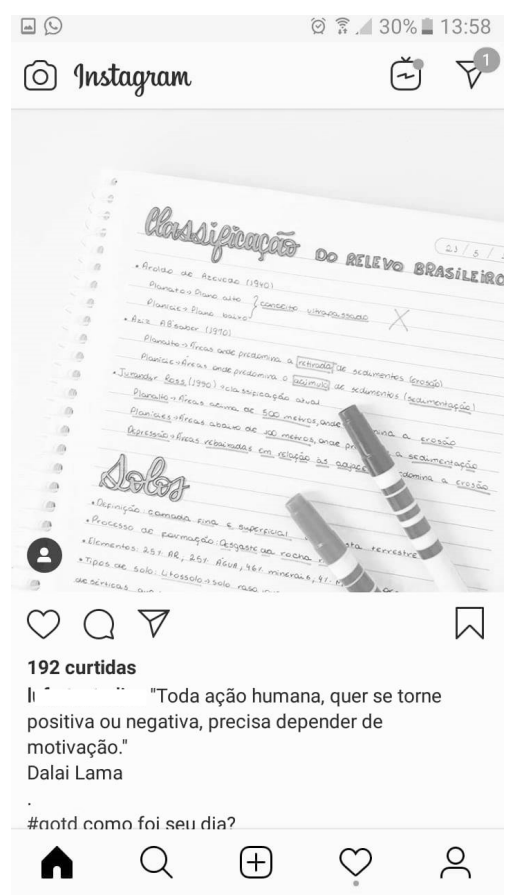

Imagem 1. Post Resumo: Relevo brasileiro 
Com base na observação da imagem 1, podemos afirmar que o studigram, como prática discursiva e multissemiótica, se constitui como um remix, no qual práticas antigas, como a elaboração de uma caligrafia desenhada, são mescladas a práticas digitais atuais. Para a produção do post, o usuário é obrigado a fotografar o trabalho manual por ele elaborado e postá-lo. Tal trabalho exige, certamente, um planejamento minucioso no qual o jovem precisa selecionar os elementos que comporão o esquema a ser apresentado, descartando informações que considere supérfluas, organizar as informações, reduzi-las para que caibam no espaço adequado, pensar no tamanho da fonte, na caligrafia, nos títulos que ficarão em destaque; além disso, há o trabalho com a produção e edição da imagem. Podemos afirmar que as ações participativas no studigram propiciam a vivência de situações de reflexão sobre as linguagens em geral e suas possibilidades de usos, contemplando as múltiplas linguagens, ou seja, os recursos multimodais, conforme orienta a BNCC.

$\mathrm{Na}$ imagem 2, podemos observar, mais uma vez, uma publicação de resumo, gênero situado no campo das práticas de estudo e pesquisa, o que nos permite refletir sobre como essas práticas sociais dialogam com situações da vida escolar, e podem ocorrer em contextos significativos para os jovens. Novamente, a produção implica evidentemente um planejamento por parte do produtor, incluindo igualmente avaliação sobre o uso das tecnologias na elaboração do resumo. Há que se considerar o espaço específico de publicação, elemento limitador da extensão do texto, exigindo a valoração estética para além do conteúdo em si, como destacado na BNCC. Pode-se observar essa valoração, inclusive, com a preocupação com a caligrafia: 


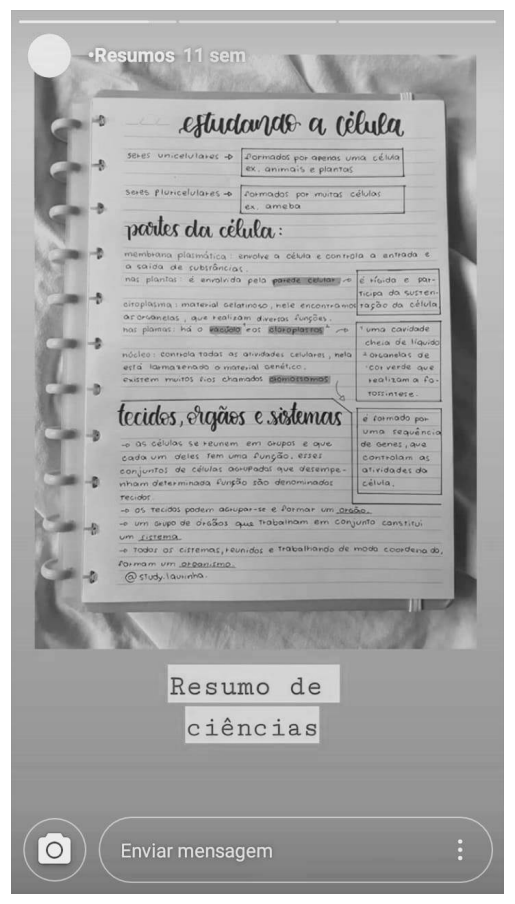

Imagem 2. Post Resumo: Ciências: Foco na caligrafia

Embora o resumo da imagem 2 utilize basicamente a linguagem escrita, não podemos ignorar a força visual da caligrafia, que põe em destaque subitens do resumo, demarcando subtemas dentro da temática "estudo da célula" que orienta a elaboração do post. O resumo de ciências expõe uma competência desenvolvida no que diz respeito à seleção e organização dos elementos textuais que compõem o gênero resumo. São hierarquizadas as informações por subtemas, são categorizados, definidos. Tal peculiaridade vem ao encontro de uma preocupação da BNCC: o jovem assume-se como curador das informações que posta, ou seja, é responsável por verificar o texto de origem, comparar informações etc.

A imagem 3, por sua vez, postada pelo mesmo usuário, demonstra a preocupação com a produção e enquadramento da imagem, chamando a atenção dos outros usuários para o fato de ser uma "imagem autoral". 

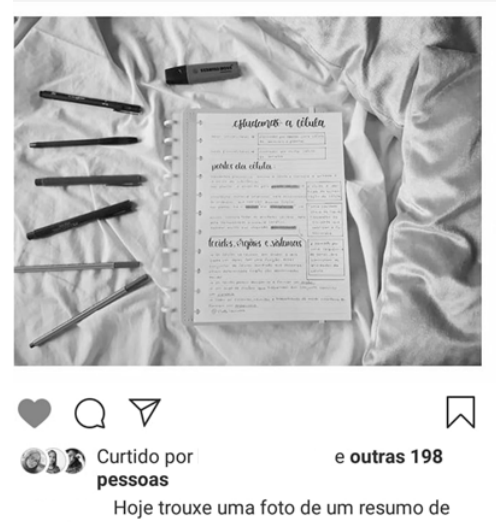

ciências que eu fiz.

Espero que tenham gostado.

Deixe sua curtida e seu comentário.

A imagem perdeu um pouco da qualidade, se vc

quiser visualiza-la melhor, vá aos destaques:

"resumos"

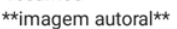

Imagem 3. Post Resumo Ciências - Foco na imagem

A publicação em uma rede social implica ser visto e, no caso específico do resumo, ser lido pelos seguidores da conta. Tal fato é atestado pela mensagem orientadora do produtor do post, sob a forma de comentário: "a imagem perdeu um pouco de qualidade, se vc quiser visualizá-la melhor, vá aos destaques". Esses processos de elaboração e divulgação de posts em um perfil colocam o jovem numa situação real de produção de textos e de sentidos. Nesse contexto, evidentemente, o produtor do post preocupa-se com o seu leitor, com a forma como ele vai avaliá-lo, pois todos desejam receber "likes". Tal processo desencadeia busca de clareza, precisão e organização na redação das informações, levando o produtor a responsabilizar-se também pela compreensão visada. Podemos afirmar, com Cabral (2013b), que o produtor do post assume assim um projeto enunciativo, assumindo autoria responsável.

$\mathrm{Na}$ imagem 4, é possível observar outro gênero do campo das práticas de estudo e pesquisa e relacionado às práticas de resumo de informações, o mapa mental: 

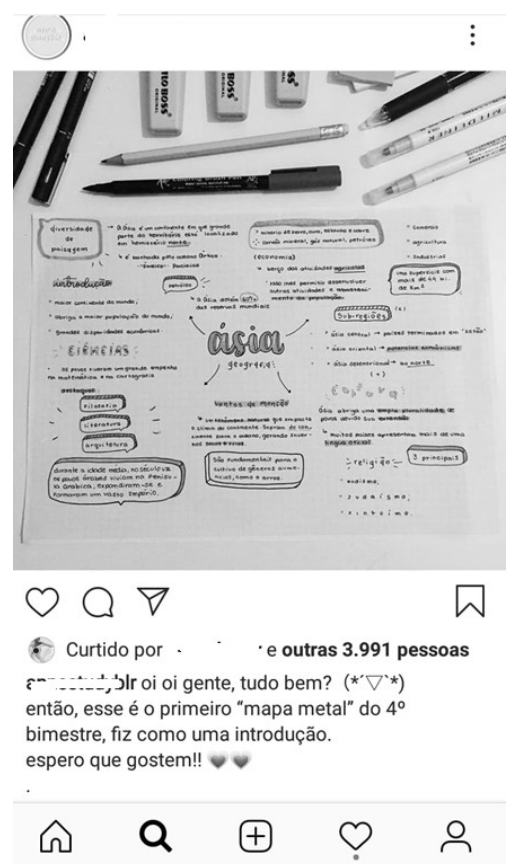

Imagem 4. Post Mapa mental

O mapa mental constitui-se como um objeto de estudo elaborado e publicado por um adolescente responsável pelo post. Trata-se de uma elaboração complexa que exige do produtor não apenas a sumarização da informação, um processo de seleção e hierarquização, mas também o estabelecimento de relações, pois as informações são organizadas por meio de associações, que permitirão ao leitor a recuperação de informações suprimidas.

Ainda na imagem 4, observamos que o responsável pelo post, produtor do mapa mental e da imagem, dialoga com seus seguidores, convidando-lhes a curtir e comentar, o que se explicita pelo seu comentário: "espero que gostem". Cumpre novamente notar que, uma vez imerso em uma rede social, o usuário espera ver e ser visto e, sobretudo, receber muitas curtidas, fruto da interação entre os participantes e fator inerente a todas as redes sociais. Tal interação instiga a participação dos jovens no processo de aprendizagem; pode-se afirmar que ela igualmente os coloca na prática cidadã de diálogo com grupos heterogêneos, uma vez que nem todos fazem parte do grupo físico de amigos da escola, por exemplo. Há, no contexto da rede social, participantes que só mantêm contato virtual. Desse ponto de vista, podemos afirmar que o studigram atende a uma demanda da BNCC, no sentido de 
capacitar os estudantes para participação na vida social e, ao mesmo tempo, lhes confere instrumentos e estratégias para práticas de estudo e pesquisa.

As imagens 5 e 6, adiante, constituem um único post, composto de duas imagens, tanto que cada uma delas é numerada, no canto direito, ao alto, com a marca $1 / 2 ; 2 / 2$, para dar indicação ao usuário da rede social de que ele deve deslizar a tela do celular para visualizar ambas as imagens em sequência. A primeira imagem (imagem 5) apresenta o título do post: "como fazer um bom resumo". Destaca-se nessa imagem a caligrafia que chama a atenção para a imagem que a sucede, a qual traz dicas de ações a seguir para a elaboração de um resumo.

Além de revelar a perspectiva instrucional adotada por muitos usuários da rede, fornecendo orientações para os demais usuários, o post revela, por parte do produtor, o desejo de interação, correspondente ao anseio pela aprovação, semelhante ao que destacamos relativamente à imagem 3. O comentário do produtor da imagem 5 traz ainda uma pergunta solicitando informações sobre o método de estudo dos demais usuários, incitando-os ao diálogo.

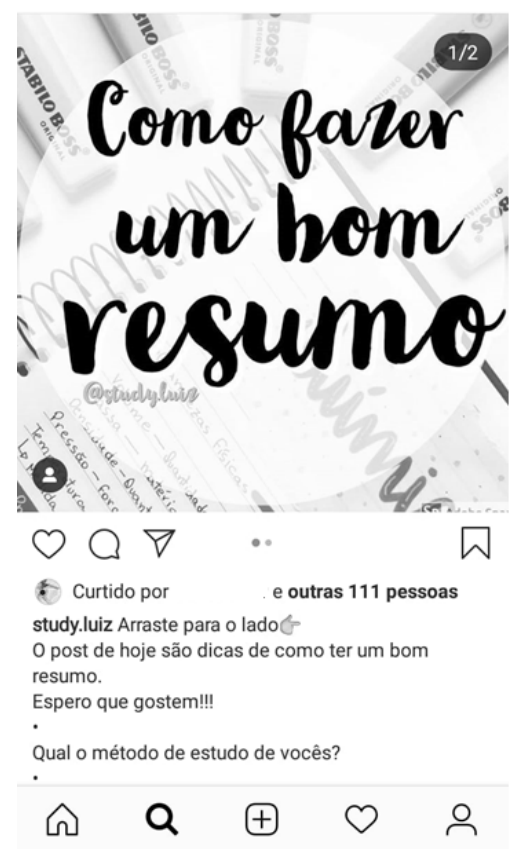

Imagem 5. Post Instruções sobre como fazer resumo 1/2

Com respeito ao estatuto de diálogo nas redes sociais vale destacar as observações de Marty (2005) ao abordar o uso das TDIC nas práticas de escrita 
na escola. Segundo essa autora, a interação com outros jovens é o que motiva os adolescentes a escrever. Sua avaliação é a de que os textos produzidos com tecnologia inscrevem-se numa perspectiva comunicativa, levando em consideração os interlocutores e a finalidade da escrita. Trata-se de uma escrita menos solitária e mais interacional, que assume outros contornos, distantes dos modelos tradicionalmente praticados na escola. De fato, o usuário das redes sociais é obrigado a se confrontar com o leitor e a considerá-lo na sua produção. Pensar no leitor como um interlocutor a ser considerado na produção do próprio texto é, de acordo com Kellog (2008), peculiar ao produtor maduro dotado de expertise.

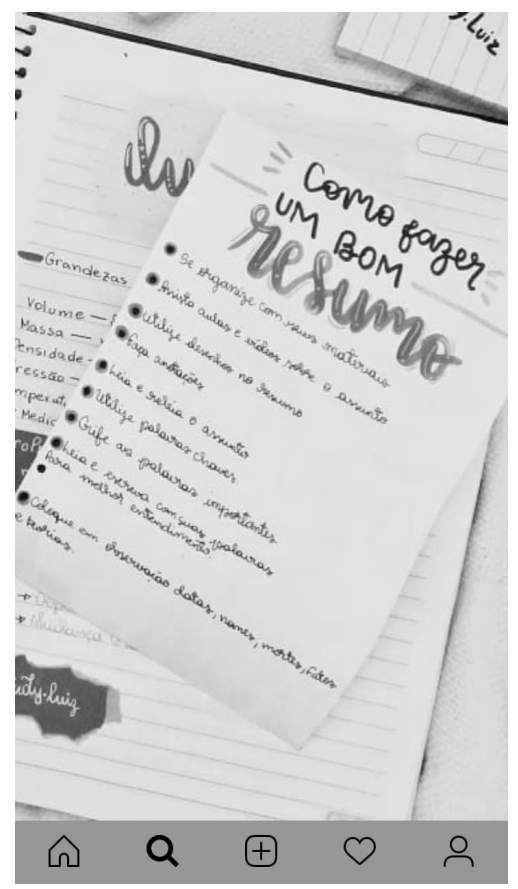

Imagem 6. Post Instruções sobre como fazer resumo 2/2

O post 2/2 (imagem 6) apresenta uma enumeração de sugestões de ações a serem tomadas por aqueles que desejam fazer um bom resumo. As orientações vão desde atitudes como "organize-se" ou "assista aulas e vídeos sobre o assunto", passando por estratégias de leitura que auxiliam na seleção de informações, como "faça anotações" ou "grife as palavras importantes", até orientações de escrita propriamente dita como "utilize palavras chaves" ou "escreva com suas palavras para melhor entendimento". Essa pluralidade de perspectivas sobre um mesmo objeto, elaboração de resumo, indica a consciência por parte do jovem produtor do post de 
que a escrita não se limita ao ato de por no papel, ela constitui um processo mais complexo que envolve organizar, planejar, produzir, revisar, conforme destacamos anteriormente neste texto.

Destaca-se, na imagem 6, o caráter interacional do post, para além do mero conteúdo injuntivo instrucional. $\mathrm{Na}$ mesma perspectiva, e também com respeito à interação entre os participantes, a imagem 7 reforça esta face das práticas de linguagem realizadas no studigram: dar instruções sobre como se organizar para estudar, por meio de verbos no imperativo.

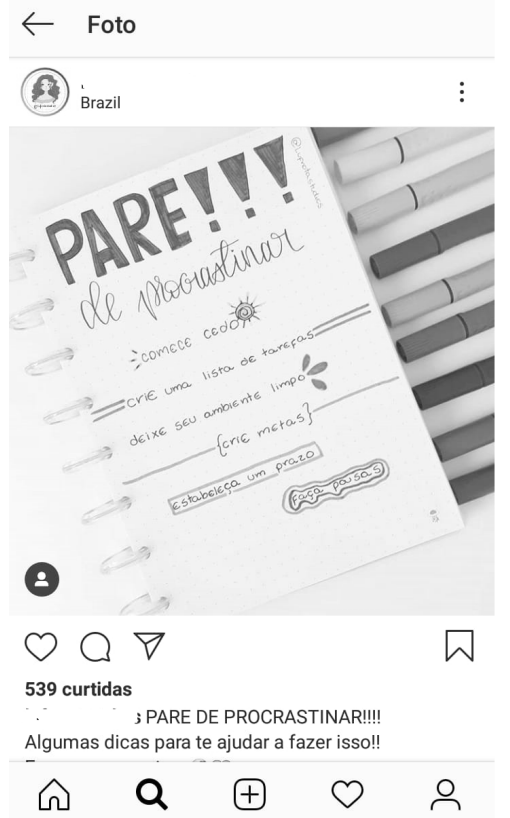

Imagem 7.Post Dicas para não procrastinar nos estudos

As "dicas" para manter os estudos consideram os demais usuários como possíveis interlocutores do produtor do post, interlocutores que necessitam de conselhos: "Pare de procrastinar". O post instaura outro tipo de interlocutor, que não é o jovem usuário interessado em estudar, mas aquele que adia os estudos, que provavelmente não corresponde ao modelo de bom aluno. O post contempla, de alguma forma, a diversidade, ao admitir que nem todo aluno é um aluno sempre dedicado aos estudos, há aqueles que procrastinam. Para esses, há conselhos. A lista de conselhos tem produção multissemiótica, apresentando elementos gráficos que retomam os enunciados verbais. Trata-se de uma outra forma de dizer que reforça o 
conselho proposto. Revela-se assim a potencialidade de construir sentidos por meio de diferentes linguagens, conforme preconiza a BNCC (BRASIL, 2018).

Com base nas análises apresentadas, podemos afirmar que as práticas desenvolvidas no perfil studigram correspondem à articulação entre as áreas do saber, por integrar práticas de escrita para interação e estudo de diversas disciplinas. No studigram podemos observar que alunos se engajam em projetos de escolhas pessoais, tal como sugere a BNCC. A esse respeito vale retomar Aubert (2016), segundo a qual os usuários de mídias digitais são ativos e engajados em ações ligadas às problemáticas do cotidiano. As considerações dessa autora nos conduzem a admitir as redes sociais como um espaço pertinente para as práticas de escrita de jovens adolescentes.

\section{PERSPECTIVAS PARA O ENSINO DA ESCRITA A PARTIR DAS PRÁtICAS MULTIMODAIS NO STUDIGRAM}

Tendo em vista as reflexões teóricas sobre os desafios impostos pelo contexto tecnológico ao ensino da escrita na educação básica e levando em conta a familiaridade da geração Z com práticas de linguagem cada vez mais multissemióticas e multimidiáticas, identificadas nos exemplos expostos na seção anterior, nesta quarta seção vamos apresentar uma sugestão didática para aplicação do studigram ao ensino da escrita, respaldados ainda nas orientações da BNCC (BRASIL, 2018) a respeito do trabalho com o componente curricular Língua Portuguesa:

Ao componente Língua Portuguesa cabe, então, proporcionar aos estudantes experiências que contribuam para a ampliação dos letramentos, de forma a possibilitar a participação significativa e crítica nas diversas práticas sociais permeadas/constituídas pela oralidade, pela escrita e por outras linguagens (BRASIL, 2018, p.67).

Pensada para aplicação no Ensino Fundamental - anos finais -, nossa proposta tem por objetivo a promoção de "redes de aprendizagem colaborativa" (BRASIL, 2018, p. 14), de modo a estabelecer uma articulação entre a Língua Portuguesa e as demais áreas do saber. A proposta visa também a levar os estudantes a assumirem o papel de protagonistas na sua formação, ampliando e qualificando sua participação nas práticas relativas ao estudo e à pesquisa, conforme previsto pela BNCC (BRASIL, 2018, p. 150), dentro do campo das práticas de estudo e pesquisa, para o ensino da Língua Portuguesa. Ressaltamos que o público alvo da proposta são os alunos do $8^{\circ}$ e $9^{\circ}$ anos, por conta da faixa etária mínima para terem uma conta na rede social Instagram. 
A proposta é a realização de um projeto integrador cujo título é "A Língua Portuguesa no mundo", para o qual os alunos farão pesquisas, envolvendo curadoria de informação e conteúdo, produção de síntese em tópicos ou resumos e produção de um texto autoral sobre o tema. Essas atividades envolvem as habilidades de planejamento, revisão e edição dos textos, além daquelas de produção e edição de fotos e/ou vídeos para divulgação em uma conta do Instagram, no perfil studigram, tendo em vista a articulação dos elementos multimodais, conforme afirma a BNCC, (BRASIL, 2018).

A fim de facilitar a compreensão, apresentamos, no quadro 1, em linhas gerais, as principais ações didáticas para aplicação da proposta, assim como as competências a ela relacionadas. Já no quadro 2, apresentamos algumas das habilidades que podem ser desenvolvidas no decorrer das etapas:

\section{Quadro 1. Projeto integrador: "A Língua Portuguesa no mundo"}

Componentes curriculares: Língua Portuguesa, História e Geografia

Duração: 1 bimestre ou 1 trimestre, a depender da organização do ano letivo da escola em que for aplicado.

Competências - área de linguagens para o Ensino Fundamental:

- Compreender as linguagens como construção humana, histórica, social e cultural, de natureza dinâmica, reconhecendo-as e valorizando-as como formas de significação da realidade e expressão de subjetividades e identidades sociais e culturais.

- Conhecer e explorar diversas práticas de linguagem (artísticas, corporais e linguísticas) em diferentes campos da atividade humana para continuar aprendendo, ampliar suas possibilidades de participação na vida social e colaborar para a construção de uma sociedade mais justa, democrática e inclusiva.

- Utilizar diferentes linguagens - verbal (oral ou visual-motora, como Libras, e escrita), corporal, visual, sonora e digital -, para se expressar e partilhar informações, experiências, ideias e sentimentos em diferentes contextos e produzir sentidos que levem ao diálogo, à resolução de conflitos e à cooperação.

- Compreender e utilizar tecnologias digitais de informação e comunicação de forma crítica, significativa, reflexiva e ética nas diversas práticas sociais (incluindo as escolares), para se comunicar por meio das diferentes linguagens e mídias, produzir conhecimentos, resolver problemas e desenvolver projetos autorais e coletivos. (BRASIL, 2018, p. 63) 


\begin{tabular}{|c|c|}
\hline Etapas & Ações didáticas \\
\hline $\begin{array}{l}\text { 1. Apresentação e } \\
\text { sensibilização para } \\
\text { o tema }\end{array}$ & $\begin{array}{l}\text { Apresentação do tema aos alunos, por meio de uma sensibilização, que pode } \\
\text { ser ouvir uma música, assistir a um filme sobre o tema. } \\
\text { Sugestão de vídeo: Língua - Vidas em Português. } \\
\text { Documentário. Brasil, Portugal, 2004,105 min., COR. Direção: Victor } \\
\text { Lopes. } \\
\text { Co-produzido por Brasil e Portugal, o documentário foi filmado em seis } \\
\text { países (Brasil, Moçambique, Índia, Portugal, França e Japão). Dirigido por } \\
\text { Victor Lopes, o longa-metragem é um mergulho nas muitas histórias da } \\
\text { língua portuguesa e na sua permanência entre culturas variadas do planeta. } \\
\text { Disponível em: < https://www.youtube.com/watch?v=JBmLzbjmhhg }> \\
\text { Acesso em junho de } 2019 \text {. } \\
\text { Roda de conversa sobre o tema, com levantamento dos conhecimentos } \\
\text { prévios dos alunos e sobre o que o filme trouxe de informações novas sobre } \\
\text { o tema. } \\
\text { Registro no caderno com observações sobre o documentário e sobre o que } \\
\text { foi comentado e discutido na roda de conversa. }\end{array}$ \\
\hline $\begin{array}{l}\text { 2. Pesquisa e } \\
\text { levantamento de } \\
\text { informações sobre } \\
\text { o tema. }\end{array}$ & $\begin{array}{l}\text { Roda de conversa sobre fontes confiáveis de pesquisa, de modo que os } \\
\text { alunos se conscientizem sobre a importância da curadoria. } \\
\text { Convite ao trabalho de pesquisa, com definição clara dos objetivos: } \\
\text { selecionar informações confiáveis, produzir síntese em tópicos e resumo; } \\
\text { produzir texto autoral sobre o tema. } \\
\text { Organização dos alunos em grupos de trabalho. } \\
\text { Sorteio dos temas: cada grupo ficará responsável por pesquisar sobre um } \\
\text { país que tenha a Língua Portuguesa como oficial. } \\
\text { Apresentação de um roteiro de pesquisa que abranja: aspectos históricos, } \\
\text { geográficos, culturais e linguísticos do país. } \\
\text { Pesquisa e levantamento das informações, dando os créditos das fontes. }\end{array}$ \\
\hline $\begin{array}{l}\text { 3. Produção de } \\
\text { síntese em tópicos } \\
\text { ou resumo }\end{array}$ & Produção de uma síntese em tópicos ou resumo. \\
\hline
\end{tabular}




\begin{tabular}{|l|l|}
\hline & $\begin{array}{l}\text { Roda de conversa sobre o uso que fazem da web (postar conteúdos, ler, obter } \\
\text { informações, fazer pesquisas de escola, estudar etc.) a fim de saber se atuam } \\
\text { nas redes sociais e, se sim, como atuam e qual a opinião que possuem sobre } \\
\text { as práticas sociais de linguagem. } \\
\text { Apresentação do perfil studigram e criação de uma conta no Instagram, com o } \\
\text { perfil studigram para cada grupo. } \\
\begin{array}{l}\text { 4. Apresentação } \\
\text { do Studigram } \\
\text { aos alunos, para } \\
\text { criação do perfil } \\
\text { e divulgação do } \\
\text { primeiro post. }\end{array}\end{array}$ \\
$\begin{array}{l}\text { Estabelecimento de regras para uso da conta, visto que seu uso será } \\
\text { pedagógico, durante a realização do projeto. } \\
\text { Produção das fotos das sínteses e/ ou resumos a serem postadas no perfil de } \\
\text { cada grupo. } \\
\text { Postagem das sínteses e resumos no studigram. } \\
\text { Interação online entre os alunos nos perfis do studigram, de modo que tomem } \\
\text { conhecimento sobre o tema do trabalho de cada grupo. }\end{array}$ \\
\hline $\begin{array}{l}\text { 5. Produção de } \\
\text { texto autoral }\end{array}$ & $\begin{array}{l}\text { Produção de um texto expositivo autoral sobre o país pesquisado, no } \\
\text { gênero folheto, com um guia de curiosidades, que servirá de base para a } \\
\text { apresentação da live na próxima etapa. }\end{array}$ \\
\hline $\begin{array}{l}\text { 6. Produção de } \\
\text { o tema live sobre } \\
\text { apresentação do } \\
\text { texto produzido. }\end{array}$ & \begin{tabular}{l} 
Preparação de uma live para exposição das curiosidades do país pesquisado. \\
\hline
\end{tabular}
\end{tabular}

Quadro 2. Algumas das habilidades a serem desenvolvidas, conforme preconiza a BNCC (BRASIL, 2018 - grifos nossos):

(EF69LP32) Selecionar informações e dados relevantes de fontes diversas (impressas, digitais, orais etc.), avaliando a qualidade e a utilidade dessas fontes, e organizar, esquematicamente, com ajuda do professor, as informações necessárias (sem excedê-las) com ou sem apoio de ferramentas digitais, em quadros, tabelas ou gráficos.
(EF69LP34) Grifar as partes essenciais do texto, tendo em vista os objetivos de leitura, produzir marginálias (ou tomar notas em outro suporte), sínteses organizadas em itens, quadro sinóptico, quadro comparativo, esquema, resumo ou resenha do texto lido (com ou sem comentário/análise), mapa conceitual, dependendo do que for mais adequado, como forma de possibilitar uma maior compreensão do texto, a sistematização de conteúdos e informações e um posicionamento frente aos textos, se esse for o caso. 
(EF69LP30) Comparar, com a ajuda do professor, conteúdos, dados e informações de diferentes fontes, levando em conta seus contextos de produção e referências, identificando coincidências, complementaridades e contradições, de forma a poder identificar erros/imprecisões conceituais, compreender e posicionar-se criticamente sobre os conteúdos e informações em questão.

(EF67LP08)* Identificar os efeitos de sentido devidos à escolha de imagens estáticas, sequenciação ou sobreposição de imagens, definição de figura/fundo, ângulo, profundidade e foco, cores/tonalidades, relação com o escrito (relações de reiteração, complementação ou oposição) etc. em notícias, reportagens, fotorreportagens, foto-denúncias, memes, gifs, anúncios publicitários e propagandas publicados em jornais, revistas, sites na internet etc.

* Embora essa habilidade esteja prevista para o $6^{\circ}$ e $7^{\circ}$ ano, no Campo Jornalístico-midiático, consideremos pertinente retomá-la nesse trabalho com o $8^{\circ}$ e $9^{\circ}$ anos, tendo em vista a multissemioses da linguagem do studigram.
(EF69LP07) Produzir textos em diferentes gêneros, considerando sua adequação ao contexto produção e circulação - os enunciadores envolvidos, os objetivos, o gênero, o suporte, a circulação -, ao modo (escrito ou oral; imagem estática ou em movimento etc.), à variedade linguística e/ ou semiótica apropriada a esse contexto, à construção da textualidade relacionada às propriedades textuais e do gênero), utilizando estratégias de planejamento, elaboração, revisão, edição, reescrita/ redesign e avaliação de textos, para, com a ajuda do professor e a colaboração dos colegas, corrigir e aprimorar as produções realizadas, fazendo cortes, acréscimos, reformulações, correções de concordância, ortografia, pontuação em textos e editando imagens, arquivos sonoros, fazendo cortes, acréscimos, ajustes, acrescentando/ alterando efeitos, ordenamentos etc.

Pensamos que, por meio dessa proposta, seja possível integrar as práticas sociais contemporâneas de linguagem, as quais são inerentes às TDIC, às práticas escolares, que pressupõem os multiletramentos e saber articular as multimodalidades, com vistas a promover a autonomia e o protagonismo estudantil, a partir de uma perspectiva que une as áreas do saber em prol do desenvolvimento da competência escrita, fundamental para a atuação na sociedade. Além disso, a proposta atrela-se a práticas sociais de linguagem, multimidiáticas, que utilizam as TDCI, próprias da cultura juvenil, nas quais são ações comuns: "produzir, configurar, disponibilizar e interagir, a partir de novas ferramentas de edição de textos, áudios, fotos e vídeos" (BRASIL, 2018, p. 68).

Em todas as etapas, os alunos são instigados a fazer a curadoria de informações, por meio da pesquisa e da seleção de dados em fontes confiáveis, em meios impressos e digitais. Em relação ao trabalho com a escrita, chamamos a atenção para a importância, na etapa 3, do momento em que o professor recupera os conhecimentos prévios dos alunos sobre os gêneros resumo e síntese em tópicos, 
gêneros próprios do campo das práticas de estudo e pesquisa. Assim, o professor orienta os alunos para a produção, de modo que eles tenham que estabelecer estratégias de escrita, e etapas de produção, revisão e reescrita, a partir de critérios já estabelecidos no início do processo de produção.

A etapa 4 trabalha diretamente com o uso das TDIC ao propor a produção e a edição da imagem a ser postada no studigram, o que deverá levar em conta os elementos multimodais e multissemióticos envolvidos no enquadramento, ângulo, cor, disposição dos elementos na imagem, além da relação entre elementos verbais e não verbais no post.

$\mathrm{Na}$ etapa 5, totalmente relacionada à escrita autoral, a ideia é que os alunos produzam um folheto, como um guia de curiosidades sobre o país, com base no conhecimento adquirido por eles durante a pesquisa. O folheto produzido será apresentado durante a live, na etapa seguinte. Essa etapa articula as TDIC à escrita em papel, conforme preconiza Plane (2008), autora para quem essa combinação traz bons resultados.

Por fim, a etapa 6, mais uma vez voltada ao uso das TDIC, prevê a execução de uma live, transmissão de vídeo, ao vivo, com a apresentação do guia de curiosidades, produto final do projeto. Nessa etapa, o aluno será instigado à prática da oralidade, por meio de uma exposição oral, porém tendo como suporte o texto escrito. Destacamos a importância de se estabelecer um tempo para a apresentação da live, e combinar um horário para que os outros grupos, e até mesmo os familiares, assistam e interajam.

\section{CONSIDERAÇÕES FINAIS}

A oficialização e a implementação da BNCC trazem novas perspectivas para o trabalho da escrita na escola, considerando os campos de atividade humana e os gêneros a eles pertinentes. $\mathrm{O}$ documento vem, sem dúvida, atender a uma demanda social emergente, pois os estudantes, embora sejam letrados no uso das redes sociais e das TDIC em geral, muitas vezes desconhecem como esses usos podem ser úteis aos seus processos de aprendizagem. Os preceitos da BNCC conduzem igualmente professores, que também são usuários das redes sociais, a trazerem para as suas práticas de ensino essa realidade da vida cotidiana.

Conforme expusemos nas análises e propostas apresentadas, a prática do studigram revela como as TDIC estão incorporadas às práticas sociais, dentre elas as práticas de estudo, porém fora do espaço escolar, tendo em vista o perfil autodidata dos frequentadores dessa rede. Tal observação nos remete aos questionamentos que 
norteiam esse trabalho: Como as redes sociais podem contribuir para as práticas escolares de ensino da Língua Portuguesa? Como utilizá-las em aula? Como desenvolver a competência escrita, na educação básica, a partir de práticas de multiletramentos vivenciadas pelos estudantes fora da escola? Acreditamos que, ao longo deste trabalho, encontramos respostas para essas perguntas. Ao final deste artigo, cremos poder afirmar que o studigram constitui-se como uma grande rede de aprendizagem; trata-se de uma rede colaborativa que se desenrola à margem da instituição escolar, mas que pode muito bem ser aproveitada nas práticas de ensino e aprendizagem voltadas para a escrita no educação básica, para um ensino significativo e real da Língua Portuguesa, especialmente nas séries finais do Ensino Fundamental.

\section{$\overline{\text { REFERÊNCIAS }}$}

AUBERT, A. (2016) Les TIC pour rendre public. In: MORELLI, P.; POGNARDCHEYNEL, N.; BALTAZART, D. (dir.). Publics et TIC Confrontations conceptuelles et recherches empiriques. Questions de Communication. Série actes. 31, p. 121-136.

BAPTISTA, D. (2017). A importância do conteúdo na Web: para uma estratégia de comunicação eficaz. In A. M. Ferreira, C. Morais, M. F. Brasete \& R. L. Coimbra (Eds.), Pelos mares da língua portuguesa III. (pp. 925-944). Disponível em: http:// hdl.handle.net/10773/18281 (acesso em 08/05/2019).

BRASIL. (2018) Base Nacional Comum Curricular: Ensino Médio. Brasília: MEC/Secretaria de Educação Básica. Disponível em: http://basenacionalcomum.mec.gov.br/ (acesso em 08/05/2019)

CABRAL, A. L. T. (2013a) Leitura de Textos Multimodais: simultaneidade e integração na construção dos sentidos IN: Intersecçôes: Revista de Estudos sobre Práticas Discursivas e Textuais. Edição especial temática: texto, interação e multimodalidade. edição 10. ano 6. número 2, p. 89-106. http://www.portal.anchieta.br/revistas-e-livros/interseccoes/ pdf/interseccoes_ano_6_numero_3.pdf (acesso em 10/05/2019)

CABRAL, A. L. T. (2013b) Plano de texto: estratégia para o planejamento da produção escrita. IN: Revista Linha D’ Água. Número 26, Universidade de São Paulo. p. 241-259. http:// www.revistas.usp.br/linhadagua/index (acesso em 12/05/2019)

CHARLES, S. (2009). Cartas sobre a Hipermodernidade ou o bipermoderno explicado às crianças. São Paulo: Barcarolla. 
CHARTIER, R. (1998). A aventura do livro: do leitor ao navegador. São Paulo: EDUNESP.

CHARTIER, R. (2011). O mundo que lê - entrevista de Roger Chartier a Carmen Guerreiro. Revista Educação, 20 de dezembro de 2011. Disponível em: https://www. revistaeducacao.com.br/o-mundo-que-le/ (acesso em 12/06/2019)

COUlmAS, F. (2014). Escrita e Sociedade. São Paulo: Parábola Editorial.

FLUSSER., V. (2010). A escrita. Há futuro para a escrita? São Paulo: AnnaBlume, [1989].

FOGEL, J-F; PATINO, B. (2013). La condition numérique. Paris: Grasset.

GEORGES, F. (2010) Identités virtuelles les profils utilisateur du web 2.0. Paris : Éditions Questions Théoriques.

KELLOGG, R. T. (2008). Training Writing Skills: a cognitive developmental perspective. In: Journal of writing research, 1 (1), p. 1-26.

KRESS, G. (2006). Reading Images: The Grammar of Visual Design. Nova York: Routledge, [1996].

LION, C. (2006). Imaginar con tecnologías relaciones entre tecnologías e conocimiento. Buenos Aires: La Crujía Ediciones.

LIPOVETSKY, G. (2004). Os tempos bipermodernos. São Paulo: Barcarolla.

MARTY, N. (2005). Informatique et nouvelles pratiques d'écriture. Cahors: Nathan.

PIMENTA, S.; BOMFANTE DOS SANTOS, Z. (2017). Linguística Textual e a perspectiva sociossemiótica da linguagem: orquestrações multimodais de significados. In: CAPISTRANO JÚNIOR, R.; LINS, M.P.P.; ELIAS, V.M. (Orgs.) Linguística Textual: Diálogos Interdisciplinares. São Paulo: Labrador, p. 387-406.

OUERFELLI, T.; GHOURABI, S. (2015). Usage pédagogique des réseaux sociaux: pratique des étudiants en Tunisie. IN: LIÉNARD, F.; ZLITNI, S (org.). La communication électronique: enjeux, stratégies, opportunités. Paris: Lambert-Lucas, p. 89-98.

PLANE, S. (2008). Reflexões sobre o uso do computador para o ensino e aprendizagem da escrita. In: MARQUESI, Sueli Cristina; ELIAS, Vanda; CABRAL, Ana Lúcia Tinoco (orgs). Interações Virtuais: perspectivas para o ensino de Lingua Portuguesa a distância. São Carlos, SP: Claraluz, p. 137-156. 
ROJO, R. (2016). Novos Letramentos, Tecnologias, Gêneros do Discurso. In: SOUZA, S.; SOBRAL, A.. (Orgs.) Gêneros entre o texto e o discurso: questões conceituais e metodológicas. Campinas, SP: Mercado de Letras, p. 127-150.

ROJO, R. H. R.; BARBOSA, J. (2015). Hipermodernidade, multimetramentos e gêneros discursivos. São Paulo: Parábola Editorial.

ROJO, R.; MELO, R. (2014). A arquitetônica bakhtiniana e os multiletramentos. In: NASCIMENTO, E.L.; ROJO, R.H.R. (Orgs.) Gêneros de texto/discurso e os desafios da contemporaneidade. Campinas, SP: Pontes Editores, (p. 249-272)

ROJO, R. (2013) Gêneros Discursivos do Círculo de Bakhtin e Multiletramentos. In: ROJO, R. (Org.).Escol@ conectada: os multiletramentos e as TICs. São Paulo: Parábola, p. 13-36.

ROJO, R. (2012). Pedagogia dos Multiletramentos: diversidade cultural e de linguagens na escola. In: ROJO, R. H. R.; MOURA, E. (Orgs.) Multimetramentos na escola. São Paulo: Parábola Editorial, p.1-19.

SANDIG, B. (2009). O Texto como conceito prototípico. IN: WEISER, H. P. e KOCH, I. V. Linguística Textual - perspectivas alemãs. Rio de Janeiro: Nova Fronteira, p. 47-72.

SANTAELLA, L. (2001). Matrizes da linguagem e pensamento: sonora, visual, verbal. São Paulo: Iluminuras/FAPESP.

Recebido: 20/06/2019

Aceito: 20/09/2019

Publicado: 1/10/2019 